\title{
A Note on This Series
}

This is the sixth in a series of volumes on topics in the humanities and the first in the new series published by Stanford University Press. This volume originated in a conference on autobiography and self-representation held at the University of California Humanities Research Institute.

For help with a broad range of problems, I am indebted to the Editorial Board of Irvine Studies in the Humanities: Ellen Burt, Lucia GuerraCunningham, Anne Friedberg, J. Hillis Miller, Jane Newman, Spencer Olin, John Carlos Rowe, Aliko Songolo (now of the University of Wisconsin), Linda Williams, and especially Murray Krieger, who chaired the board while this volume was under consideration. I am grateful to former Dean Terence D. Parsons of the School of Humanities for his support. Joann McLean and Lisa Ness provided secretarial help for Irvine Studies. Philip Baruth, our Research Assistant, proofread the text and compiled the index, among other contributions. His own interest in and knowledge of autobiography proved valuable. My undergraduate mentees Georgina Dodge, now a Mellon Fellow at UCLA, and Maria Iannetta, now a President's Fellow at the University of California, Santa Cruz, were also helpful. Helen Tartar, Humanities Editor at Stanford University Press, is responsible for the new series and I am particularly indebted to her for this volume.

Robert Folkenflik, General Editor 
